\title{
Insertion of a self-expanding metal stent for a stomal stenosis
}

Stenosis is one of the major complications of a gastrointestinal stoma, yet its treatment is not well established [1-3]. We report a case of stomal stenosis that improved after insertion of a temporary self-expanding metal stent (SEMS). A 61-year-old woman presented with a stoma that had been malfunctioning for 2 months. She had been diagnosed with recurrent cervical cancer and admitted 7 months previously because of lifethreatening rectal bleeding. The bleeding had come from a branch of the internal iliac artery and had passed through a tract formed between the rectum and the recurrent cervical cancer by a necrotic abscess. She had been treated with emergent transarterial embolization and coiling and had subsequently undergone a T-loop transverse colostomy with stoma formation to prevent stool passing into the tract. For the past 2 months, however, her stools had been mainly passing out through her urethra and anus, rather than through the stoma.

A computed tomography (CT) scan revealed a tight stenosis at the stoma ( $\bullet$ Fig. 1). We therefore inserted a custom-built SEMS (morning glory-shaped distal end, partially covered, $8 \mathrm{~cm}$ in length, $22 \mathrm{~mm}$ in diameter; Hanarostent; M.I.Tech, Seoul, South Korea) into the stomal tract. The SEMS was fixed to the stomal opening with a baseplate for stomal care (SenSura Click; Coloplast Ltd. Hong Kong, China; $\bullet$ Fig. 2). She was commenced on a stool softener and the SEMS was passed from the stomal tract with the stool 3 days later.

We reinserted another custom-built, large-sized SEMS (distal flared, fully covered, $12 \mathrm{~cm}$ in length, $28 \mathrm{~mm}$ in diameter; Hanarostent; M.I.Tech) into the stomal tract using fluoroscopic guidance ( $\bullet$ Fig.3). The SEMS was fixed to the stomal opening with a surgical thread, a plastic ring, and a baseplate for stomal care ( Fig.4). Following this, her stools were mainly passed through the SEMS, which was kept in position for 2 weeks ( Fig.5). Although the functioning of her stoma was maintained for over 2 months, the patient died because of cancer complications.
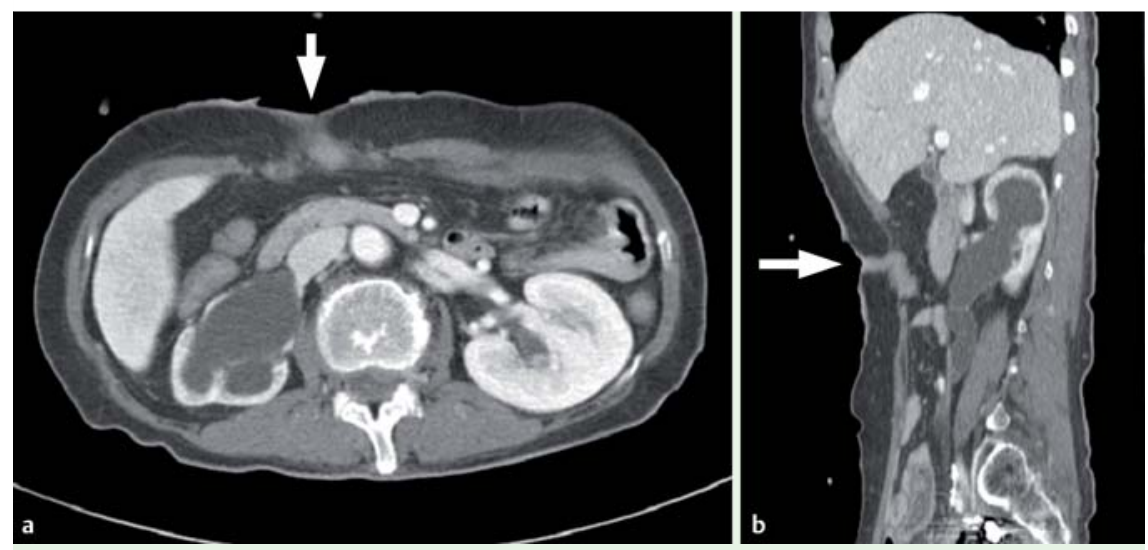

Fig. 1 Computed tomography (CT) scan demonstrating a tight stenosis at the stoma (white arrow) in: a axial view; $\mathbf{b}$ sagittal view.

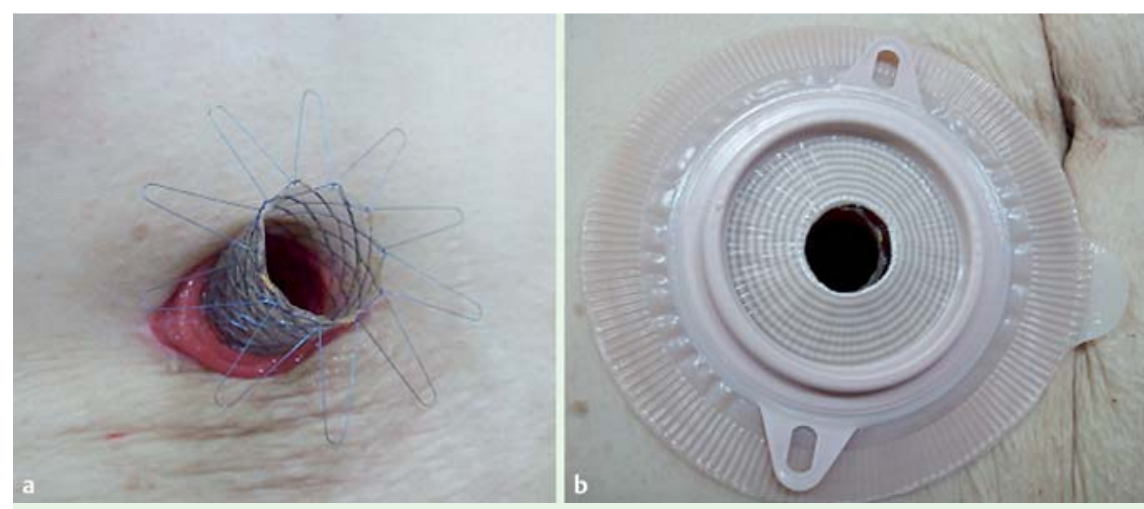

Fig. 2 Photographs during and after insertion of the self-expanding metal stent (SEMS) showing: a the morning glory-shaped, external end of the SEMS; $\mathbf{b}$ the baseplate for stomal care, to which the external end of the SEMS was fixed.
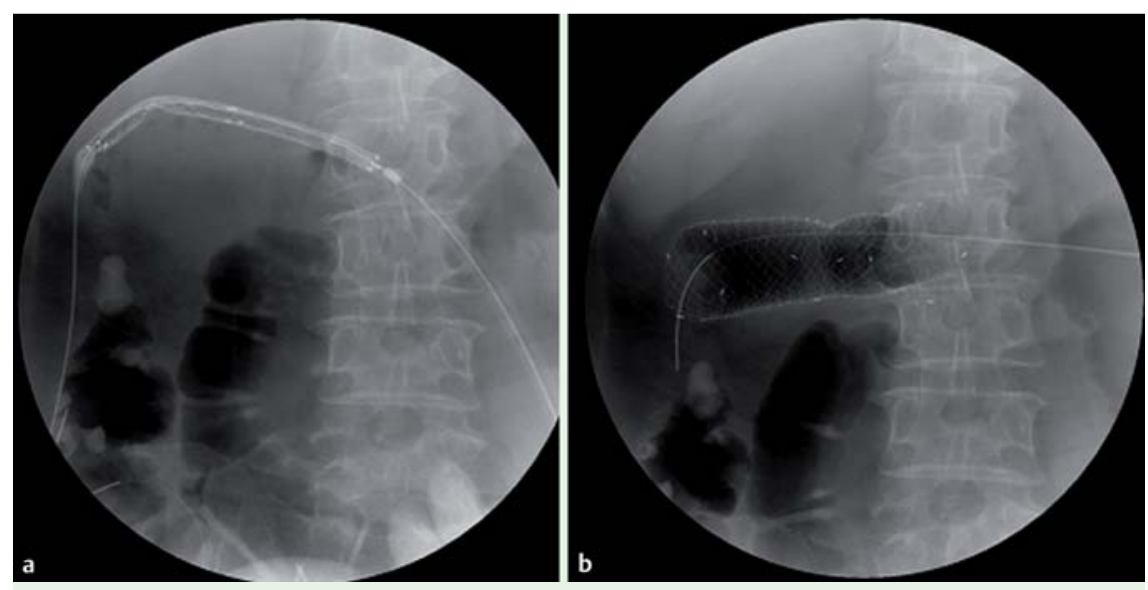

Fig. 3 Fluoroscopic views during the insertion of the second self-expanding metal stent (SEMS) showing: a the SEMS being inserted; $\mathbf{b}$ the expanded SEMS in situ. 


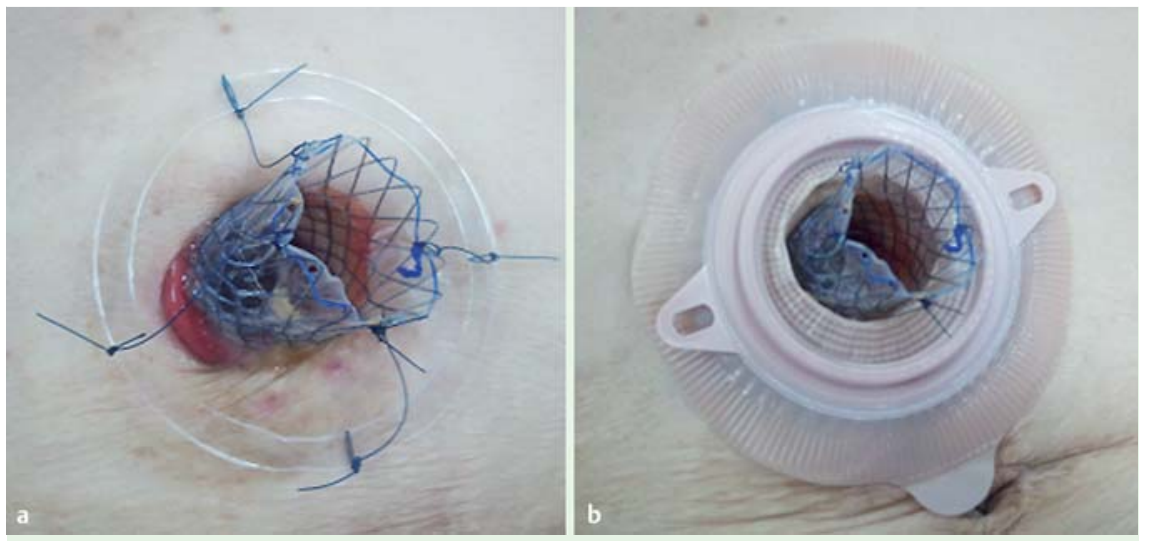

Fig. 4 Photographs of the stoma showing: a the external end of the large-sized, distal-flared SEMS after suturing to the plastic ring; $\mathbf{b}$ the baseplate for stomal care in position around the stoma and SEMS.

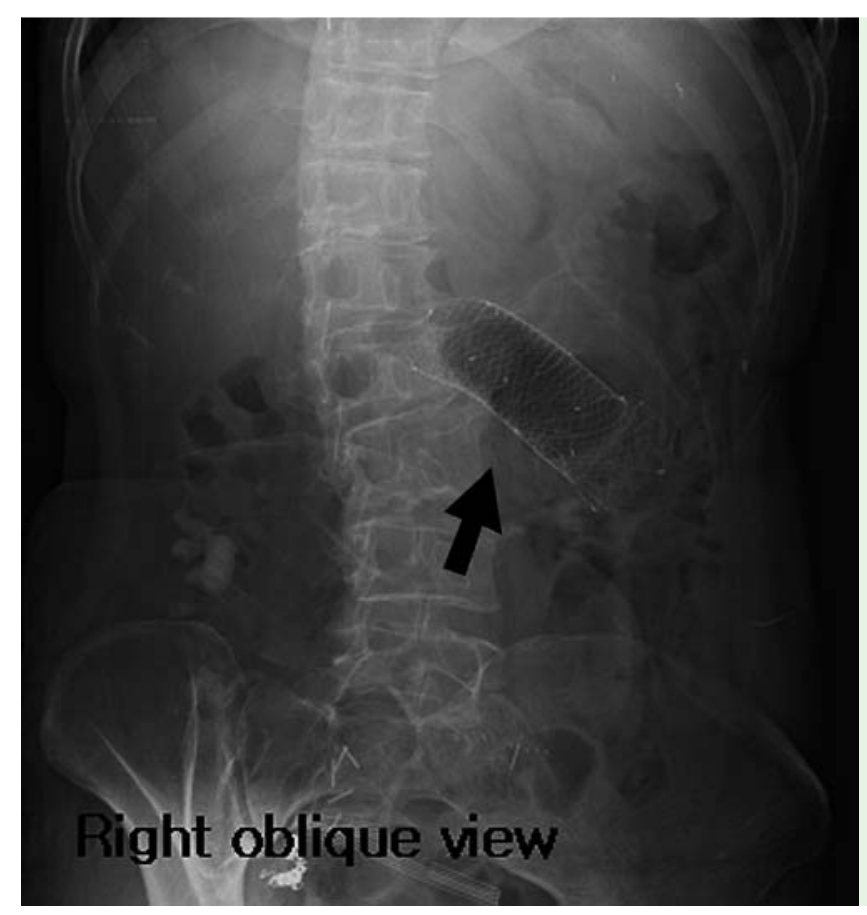

Endoscopy_UCTN_Code_TTT_1AQ_2AF

\section{Competing interests: None}

\author{
W. H. Kim¹, C.-I. Kwon' ${ }^{1}$, J. W. Kim¹, \\ C. Lee $^{2}$
}

${ }^{1}$ Digestive Disease Center, CHA Bundang Medical Center, CHA University, Seongnam, South Korea

2 Comprehensive Gynecologic Cancer Center, CHA Bundang Medical Center, CHA University, Seongnam, South Korea

\section{References}

1 Robertson I, Eung E, Hughes D et al. Prospective analysis of stoma related complications. Colorectal Dis 2005; 7: 279-285

Fig. 5 Abdominal radiograph showing the position of the selfexpanding metal stent (SEMS; black arrow) after insertion.

2 Duchesne JC, Wang YZ, Weintraub SL et al. Stoma complications: a multivariate analysis. Am Surg 2002; 68: 961 -966

3 Shabbir J, Britton DC. Stoma complications: a literature overview. Colorectal Dis 2010; 12 : 958-964

\section{Bibliography}

DOI http://dx.doi.org/

10.1055/s-0032-1306904

Endoscopy 2012; 44: E143-E144

(c) Georg Thieme Verlag KG

Stuttgart · New York

ISSN 0013-726X

\section{Corresponding author}

\section{C.-I. Kwon, MD}

Digestive Disease Center

CHA Bundang Medical Center, CHA University

351 Yatap-dong, Bundang-gu

Seongnam, 463-712

South Korea

Fax: +82-31-7805219

endoscopy@cha.ac.kr 